\title{
Return Period of a Sea Storm with at Least Two Waves Higher than a Fixed Threshold
}

\author{
Felice Arena, Giuseppe Barbaro, and Alessandra Romolo \\ Natural Ocean Engineering Laboratory, Department DICEAM, “Mediterranea” University, 89122 Reggio Calabria, Italy \\ Correspondence should be addressed to Felice Arena; arena@unirc.it
}

Received 12 August 2012; Revised 8 January 2013; Accepted 28 January 2013

Academic Editor: P. Liatsis

Copyright (C) 2013 Felice Arena et al. This is an open access article distributed under the Creative Commons Attribution License, which permits unrestricted use, distribution, and reproduction in any medium, provided the original work is properly cited.

\begin{abstract}
Practical applications in ocean engineering require the long-term analysis for prediction of extreme waves, that identify design conditions. If extreme individual waves are investigated, we need to combine long-term statistical analysis of ocean waves with short-term statistics. The former considers the distribution of standard deviation of free surface displacement in the considered location in a long-time span, of order of 10 years or more. The latter analyzes the distribution of individual wave heights in a sea state, which is a Gaussian process in time domain. Recent advanced approaches enable the combination of the two analyses. In the paper the analytical solution is obtained for the return period of a sea storm with at least two individual waves higher than a fixed level. This solution is based on the application of the Equivalent Triangular Storm model for the representation of actual storms. One of the corollaries of the solution gives the exact expression for the probability that at least two waves higher than fixed level are produced during the lifetime of a structure. The previous solution of return period and the relative probability of exceedance may be effectively applied for the risk analysis of ocean structures.
\end{abstract}

\section{Introduction}

The concept of Equivalent Triangular Storm (ETS) was introduced by Boccotti in the eighties $[1,2]$. A complete analysis was then given in Boccotti [3], where the ETS model was applied for solving in a closed form of some long-term problems, which are very useful for the design of coastal and offshore structures.

In other words, the ETS model represents each actual storm as a triangle, where the triangle height is equal to the maximum significant wave height during the actual storm and the triangle base is such that the maximum expected wave height in the actual storm is equal to the maximum expected wave height in the triangular storm. Then, the triangle height is achieved from the significant wave height time series of the storm, while the triangle base is calculated by means of an iterative procedure.

If the equivalent sea is considered, which is given by substituting a sequence of triangles to the sequence of actual storms, some analytical solutions were found for the return period of severe storms. Boccotti [3] found the analytical solution for the return period $R(H)$ of a sea storm in which the highest wave has height exceeding a fixed threshold $H$.

The solution for the return period $R(H)$ was then given, with a different formal derivation, by Arena and Pavone [4]. They considering the ETS approach combined the longterm and the second-order crest height distribution $[5,6]$ to achieve the return period $R(C)$ of a sea storm in which the highest nonlinear crest height exceeds a fixed threshold $C$.

Recently, Arena and Pavone [7] proposed a generalized approach for the long-term modelling of extreme waves, by giving the general expression of the return period $R_{N}(H)$ of a sea storm in which exactly $N$ waves higher than $H$ occur. Following this approach the solution is also given for the return period $R_{\geq N}(H)$ of a sea storm in which at least $N$ waves larger than a fixed threshold $H$ occur, with $N=1,2,3$, and so forth.

Different approaches to combine short- and long-term statistics were proposed by [8], who gave a generalization of Borgman's results [9] and by Tromans and Vanderschuren [10] and Forristall [11], who introduced the analysis of extreme waves during storms and considered the loads and response on structures for engineering applications. 
In this paper, by following a different logic, with respect to that one adopted by Arena and Pavone [7], a new solution is found for the return period $R_{\geq 2}^{\prime}(H)$ of a sea storm in which at least two waves higher than a fixed threshold $H$ occur. The new solution for $R_{\geq 2}^{\prime}(H)$ is achieved from direct combination of short-term and long-term wave statistics, while the Arena and Pavone solution gave the $R_{\geq 2}(H)$ solution as a function of both $R_{\geq 1}(H)$ and $R_{1}(H)$ by means of the following expression:

$$
\frac{1}{R_{\geq 2}(H)}=\frac{1}{R_{\geq 1}(H)}-\frac{1}{R_{1}(H)},
$$

where $R_{\geq 1}(H)$ and $R_{1}(H)$ are the return periods of a sea storm in which, respectively, (i) at least a wave higher than $H$ occurs; (ii) a single wave higher than $H$ occurs.

The final comparison between the two solutions, which is proposed starting from NOAA-NODC (USA) buoys data and from Italian buoys network (RON), from ISPRA, Institute for Environmental Protection and Research (Italy), shows a full agreement. This result confirms that the Equivalent Triangular Storm (as well as the Equivalent Power Storm by Fedele and Arena [12]) model is very powerful to determine the long-term statistics of extreme waves during storms (see also Arena et al. [13]).

The results are of interest for engineering applications, because they enable to perform a complete analysis of extreme waves that we may expect in the lifetime of a structure, which may be, for example, either an offshore structure [14-19] or on an upright breakwater (see, e.g., Boccotti et al. $[14,15]$ and Romolo and Arena $[20,21])$. This may be done in terms of return value of the extreme individual crest-totrough wave height, as well as by achieving the second wave (the third and so on), in terms of height, occurring in a fixed time span on the considered structure.

\section{Return Period $R_{\geq 2}^{\prime}(H)$ of a Sea Storm in Which at Least Two Waves Higher than a Fixed Threshold $H$ Occur}

The return period $R_{\geq 2}^{\prime}(H)$ of a sea storm in which at least two waves higher than a fixed threshold $H$ occur may be defined, in alternative, as the return period of a sea storm in which the second wave height (if waves are ordered by decreasing crest-to-trough wave heights) is larger than $H$.

If a large time span $\tau$ is considered, we may define

$$
R_{\geq 2}^{\prime}(H)=\frac{\tau}{N_{I I}(H, \tau)},
$$

with $N_{I I}(H, \tau)$ the number of waves, during $\tau$, which are (i) higher than $H$; (ii) the second waves (if waves occurring in the storm are ordered by decreasing height) in their own storm. In the following, the solution is given for $N_{I I}(H, \tau)$. Let us consider the Triangular Sea, which is given by the sequence of equivalent triangular storms.

The number of waves with height between $x$ and $x+\mathrm{d} x$, occurring in sea states with significant wave height $H_{s}$ in $(h, h+\mathrm{d} h)$ in the triangular storms with height between $a$ and $a+\mathrm{d} a$ and base between $b$ and $b+\mathrm{d} b$, during $\tau$, is

$$
\begin{aligned}
& {\left[p_{A}(a) \mathrm{d} a N(\tau) p_{B}(b \mid a) \mathrm{d} b\right] \Delta t(h, \mathrm{~d} h, a, b)} \\
& . \frac{p\left(x ; H_{s}=h\right) \mathrm{d} x}{\bar{T}(h)}
\end{aligned}
$$

where $N(\tau)$ is the number of triangles during $\tau, P_{A}(a)$ is the probability density function of the triangle heights, $P_{B}(b \mid a)$ is the probability density function of the triangle base, with given height $a$, and $\Delta t(h, \mathrm{~d} h, a, b)$ is the time in which the significant wave height $H_{s}$ is in the range $(h, h+\mathrm{d} h)$ in those triangles with height $a$ and base $b$. Finally, $p\left(x ; H_{s}=h\right)$ is the probability density function of the wave height in a sea state with $H_{s}=h$, and $\bar{T}(h)$ is Rice's mean period [22, 23].

It follows that the number $N_{I I}(x, h ; a, b)$ of waves with height between $x$ and $x+\mathrm{d} x$, occurring in sea states with significant wave height $H_{s}$ in $(h, h+\mathrm{d} h)$ in the triangular storms with height between $a$ and $a+\mathrm{d} a$ and base between $b$ and $b+\mathrm{d} b$, during $\tau$, which are the second in order of height in their own storm, is given by

$$
\begin{aligned}
N_{I I}(x, h ; a, b) & \\
= & {\left[p_{A}(a) \mathrm{d} a N(\tau) p_{B}(b \mid a) \mathrm{d} b\right] \Delta t(h, \mathrm{~d} h, a, b) } \\
& \cdot \frac{p\left(x ; H_{s}=h\right) \mathrm{d} x}{\bar{T}(h)} P_{2}(x, h ; a, b),
\end{aligned}
$$

where, in a triangular storm with height $a$ and base $b$, given that a wave with height between $x$ and $x+d x$ occurs in a sea state with significant wave height between $h$ and $h+d h$, $P_{2}(x, h ; a, b)$ is the probability that:

(i) just a wave higher than $x$ will occur;

(ii) all the other waves of the sea storm will have height smaller than $x$.

More in general, if an actual storm is considered, $P_{2}$ is the probability that a wave with height between $x$ and $x+\mathrm{d} x$, occurring in a sea state with significant wave height between $h$ and $h+\mathrm{d} h$, is the second wave in height in its own storm. It is then given by

$$
\begin{aligned}
P_{2}= & \frac{1}{1-P\left(x ; H_{s}=h\right)} \\
& \times\left[-\frac{P\left(x ; H_{s}=h\right)}{1-P\left(x ; H_{s}=h\right)}+\sum_{i=1}^{N} \frac{P\left(x ; H_{s}=h_{i}\right)}{1-P\left(x ; H_{s}=h_{i}\right)} N_{i}\right] \\
& \times \prod_{i=1}^{N}\left[1-P\left(x ; H_{s}=h_{i}\right)\right]^{N_{i}},
\end{aligned}
$$




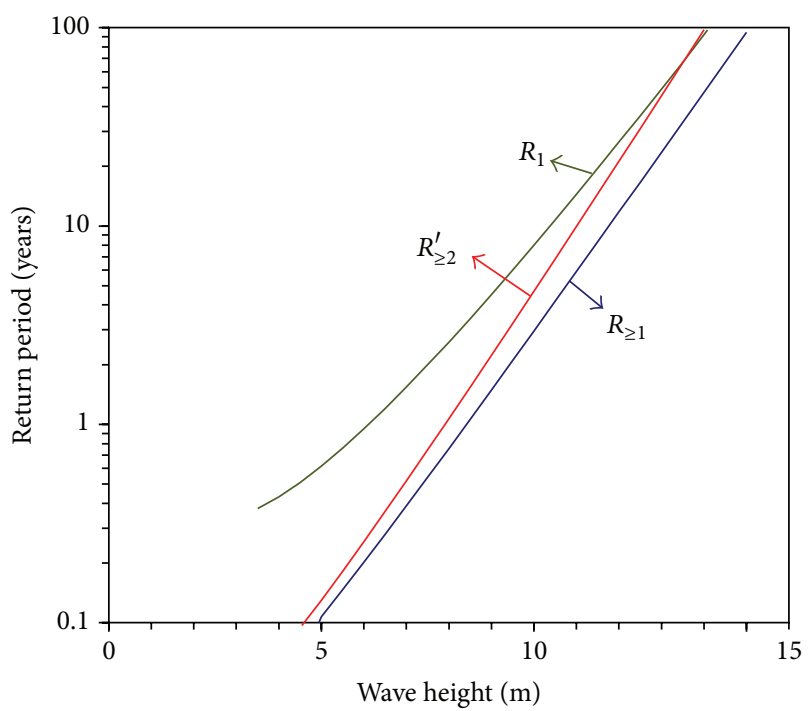

Figure 1: Return periods $R_{\geq 2}^{\prime}(H), R_{\geq 1}(H)$, and $R_{1}(H)$, calculated from data of RON buoy of Crotone (Italy), with the parameters defined in the Appendix.

where $N$ is the number of the sea states in the storm. Equation (5), in integral form, may be rewritten as $[9,24]$

$$
\begin{aligned}
P_{2}= & \frac{1}{1-P\left(x ; H_{s}=h\right)} \\
\times & {\left[-\frac{P\left(x ; H_{s}=h\right)}{1-P\left(x ; H_{s}=h\right)}\right.} \\
& \left.\quad+\int_{0}^{D} \frac{P\left[x ; H_{s}=h(t)\right]}{1-P\left[x ; H_{s}=h(t)\right]} \frac{1}{\bar{T}[h(t)]} \mathrm{d} t\right] \\
& \cdot \exp \left\{\int_{0}^{D} \ln \left[1-P\left(x ; H_{s}=h(t)\right)\right] \frac{1}{\bar{T}[h(t)]} \mathrm{d} t\right\},
\end{aligned}
$$

where $D$ is the storm duration.

If the triangular sea is considered, for a sea storm with height $a$ and base $b$, the probability $P_{2}(x, h ; a, b)$ is given by

$$
\begin{aligned}
& P_{2}(x, h ; a, b) \\
& =\frac{1}{1-P\left(x ; H_{s}=h\right)} \\
& \times\left[-\frac{P\left(x ; H_{s}=h\right)}{1-P\left(x ; H_{s}=h\right)}+\frac{\bar{b}(a)}{a}\right. \\
& \left.\times \int_{0}^{a} \frac{P\left(x ; H_{s}=h^{\prime \prime}\right)}{1-P\left(x ; H_{s}=h^{\prime \prime}\right)} \frac{1}{\bar{T}\left(h^{\prime \prime}\right)} \mathrm{d} h^{\prime \prime}\right] \\
& . \exp \left[\frac{\bar{b}(a)}{a} \int_{0}^{a} \frac{\ln \left[1-P\left(x ; H_{s}=h^{\prime}\right)\right]}{\bar{T}\left(h^{\prime}\right)} \mathrm{d} h^{\prime}\right] \text {. }
\end{aligned}
$$

TABLE 1: Parameters of the Weibull significant wave height distribution (A4) and of the base height regression (A5) for some locations (from [25]).

\begin{tabular}{lccccc}
\hline $\begin{array}{l}\text { Buoy } \\
\text { Location }\end{array}$ & $\begin{array}{c}C_{1} \\
(\text { hour })\end{array}$ & $\begin{array}{c}C_{2} \\
\left(\mathrm{~m}^{-1}\right)\end{array}$ & $u$ & $\begin{array}{c}w \\
(\mathrm{~m})\end{array}$ & $\begin{array}{c}h_{l} \\
(\mathrm{~m})\end{array}$ \\
\hline $\begin{array}{l}\text { NDBC } 46004 \\
51.0^{\circ} \mathrm{N}-136.0^{\circ} \mathrm{W}\end{array}$ & 110.25 & $6.43 \cdot 10^{-2}$ & 1.484 & 2.489 & 0.65 \\
$\begin{array}{l}\mathrm{NDBC} 44008 \\
40.5^{\circ} \mathrm{N}-69.4^{\circ} \mathrm{W}\end{array}$ & 75.6 & $5.57 \cdot 10^{-2}$ & 1.100 & 1.146 & 0.55 \\
$\begin{array}{l}\text { RON Crotone } \\
39.0^{\circ} \mathrm{N}-17.2^{\circ} \mathrm{E}\end{array}$ & 91.84 & $3.48 \cdot 10^{-2}$ & 0.956 & 0.590 & 0.08 \\
\hline
\end{tabular}

The number of waves, during $\tau$, which are higher than $H$ and the second in their own storm, is

$$
N_{I I}(H, \tau)=\int_{H}^{\infty} \int_{0}^{\infty} \int_{h}^{\infty} \int_{0}^{\infty} N_{I I}(x, h ; a, b) \mathrm{d} b \mathrm{~d} a \mathrm{~d} h \mathrm{~d} x .
$$

In conclusion, combining (2), (4), (7), and (8), the expression is given for the return period $R_{\geq 2}^{\prime}(H)$ of a sea storm in which at least two waves higher than a fixed threshold $H$ occur:

$$
\begin{aligned}
R_{\geq 2}^{\prime}(H) & \left\{\int_{H}^{\infty} \int_{0}^{\infty} \frac{1}{\bar{T}(h)} p\left(x ; H_{s}=h\right) \frac{1}{1-P\left(x ; H_{s}=h\right)}\right. \\
& \cdot \int_{h}^{\infty}-\frac{\mathrm{d} p\left(H_{s}=a\right)}{\mathrm{d} a} \\
& \times \exp \left[\frac{\bar{b}(a)}{a} \int_{0}^{a} \frac{\ln \left[1-P\left(x ; H_{s}=h^{\prime}\right)\right]}{\bar{T}\left(h^{\prime}\right)} \mathrm{d} h^{\prime}\right] \\
& \cdot\left[\frac{\bar{b}(a)}{a} \int_{0}^{a} \frac{1}{\bar{T}\left(h^{\prime \prime}\right)} \frac{P\left(x ; H_{s}=h^{\prime \prime}\right)}{1-P\left(x ; H_{s}=h^{\prime \prime}\right)} \mathrm{d} h^{\prime \prime}+\right. \\
& \left.\left.\quad-\frac{P\left(x ; H_{s}=h\right)}{1-P\left(x ; H_{s}=h\right)}\right] \mathrm{d} a \mathrm{~d} h \mathrm{~d} x\right\}^{-1},
\end{aligned}
$$

where, according to conclusions of Arena and Pavone [4], the bases of the triangular storms may be considered constant $(\bar{b})$ with respect to $a$, because $a$ and $b$ are stochastically independent to each other; alternatively the Dirac distribution may be considered [3], because it is slightly conservative: in this case the function $\bar{b}(a)$ may be represented by means of a regression, as given in the Appendix.

Figure 1 shows the return period $R_{\geq 2}^{\prime}(H)$, which has been calculated by considering functions defined in the Appendix. Values of parameters used for calculation are defined in Table 1. 


\section{An Alternative Approach for Calculation of $R_{\geq 2}(H)$}

A different approach for calculation of the return period $R_{\geq 2}(H)$ was given by Arena and Pavone [7], by means of (1). In that equation, $R_{\geq 1}(H)$ represents the return period of a sea storm in which the maximum wave height exceeds the threshold $H$, and $R_{1}(H)$ represents the return period of a sea storm during which one wave only with crest-to-trough height larger than a fixed threshold $H$ occurs.

For the calculation of $R_{\geq 1}(H)$, the solution given by Arena and Pavone [4] has been applied:

$$
\begin{aligned}
& R_{\geq 1}(H) \\
& =-\left\{\int_{0}^{\infty} \frac{\mathrm{d} p\left(H_{s}=a\right)}{\mathrm{d} a} \frac{a}{\bar{b}}\right. \\
& \times\left[1-\exp \left(\frac{\bar{b}}{a} \int_{0}^{a} \frac{1}{\bar{T}\left(h^{\prime}\right)}\right.\right. \\
& \left.\left.\left.\times \ln \left[1-P\left(H ; H_{s}=h^{\prime}\right)\right] \mathrm{d} h^{\prime}\right)\right] d a\right\}^{-1} .
\end{aligned}
$$

The return period $R_{1}(H)$ is calculated by considering the following expression [7]:

$$
\begin{aligned}
& R_{1}(H) \\
& =-\left\{\int_{0}^{\infty} \frac{\mathrm{d} p\left(H_{s}=a\right)}{\mathrm{d} a} \frac{a}{\bar{b}}\right. \\
& \times\left[\int_{0}^{a} \frac{P\left(H ; H_{s}=h\right)}{\bar{T}(h)\left[1-P\left(H ; H_{s}=h\right)\right]} \mathrm{d} h\right] \\
& \left.\cdot \exp \left[\frac{\bar{b}}{a} \int_{0}^{a} \frac{\ln \left[1-P\left(H ; H_{s}=h^{\prime}\right)\right]}{\bar{T}\left(h^{\prime}\right)} \mathrm{d} h^{\prime}\right] \mathrm{d} a\right\}^{-1} .
\end{aligned}
$$

\section{The Encounter Probability}

In general, the occurrences of severe storms are assumed to form a homogeneous Poisson process. Then, the probability that in the given time interval $L$ (which, in the design of ocean structures, may be considered equal to the lifetime of the structure) at least a sea storm with given properties occurs, may be written as

$$
P(L, R)=1-\exp \left(-\frac{L}{R}\right)
$$

where $R$ is the return period of the considered storm.

Then, if we assume that

(a) the occurrences of the sea storms in which the highest wave is larger than $H$,

(b) the occurrences of the sea storms in which just a wave higher than $H$ occurs, (c) the occurrences of the sea storms in which at least two waves with height larger than $H$ occur

will represent the Poisson processes, we have, for example, that the probability that during $L$ at least a storm will occur, with the maximum wave height larger than $H$ is

$$
P_{a}\left[L, R_{\geq 1}(H)\right]=1-\exp \left[-\frac{L}{R_{\geq 1}(H)}\right] .
$$

Equation (13) gives the probability that the maximum wave height in the lifetime (time) $L$ will be greater than $H$.

More in general, if we define

(i) $\Pi_{a}(L, N)$ as the probability that $N$ occurrences of the process $(a)$ will occur in the time span $L$,

(ii) $\Pi_{b}(L, N)$ as the probability that $N$ occurrences of the process $(b)$ will occur in the time span $L$,

(iii) $\Pi_{c}(L, N)$ as the probability that $N$ occurrences of the process $(c)$ will occur in the time span $L$,

(the processes $a, b$, and $c$ being defined above), it follows that

$$
P^{I}=1-\Pi_{a}(L, 0)-\Pi_{b}(L, 1) \Pi_{c}(L, 0)
$$

represents the probability that the second wave, in order of height, during the time $L$ will be higher than $H$;

$$
P^{I I}>\Pi_{c}(L, 1) \Pi_{b}(L, 0)
$$

represents the probability that the second wave, in order of height, higher than $H$, during the time $L$, will occur in the same storm in which the highest wave happens;

$$
P^{I I I} \equiv \frac{P^{I I}}{P^{I}}>\frac{\Pi_{c}(L, 1) \Pi_{b}(L, 0)}{1-\Pi_{a}(L, 0)-\Pi_{b}(L, 1) \Pi_{c}(L, 0)}
$$

represents the probability that, given that the second wave in order of height during $L$ is higher than $H$, it will belong to the same storm of the highest wave. In other words, $P^{I I I}$ $\left(\equiv P^{I I} / P^{I}\right)$ is the probability that the two highest waves in the time (lifetime) $L$ will occur during the same sea storm.

Note that both $P^{I I}$ and $P^{I I I}$ have been defined by considering the stochastic independence of the processes $(b)$ and (c).

Finally, if the Poisson processes are considered, the probabilities defined in this section may be calculated as

$$
\begin{aligned}
& \Pi_{a}(L, 0)=\exp \left[-\frac{L}{R_{\geq 1}(H)}\right], \\
& \Pi_{b}(L, 0)=\exp \left[-\frac{L}{R_{1}(H)}\right], \\
& \Pi_{c}(L, 0)=\exp \left[-\frac{L}{R_{\geq 2}(H)}\right], \\
& \Pi_{b}(L, 1)=\frac{L}{R_{1}(H)} \exp \left[-\frac{L}{R_{1}(H)}\right], \\
& \Pi_{c}(L, 1)=\frac{L}{R_{\geq 2}(H)} \exp \left[-\frac{L}{R_{\geq 2}(H)}\right] .
\end{aligned}
$$




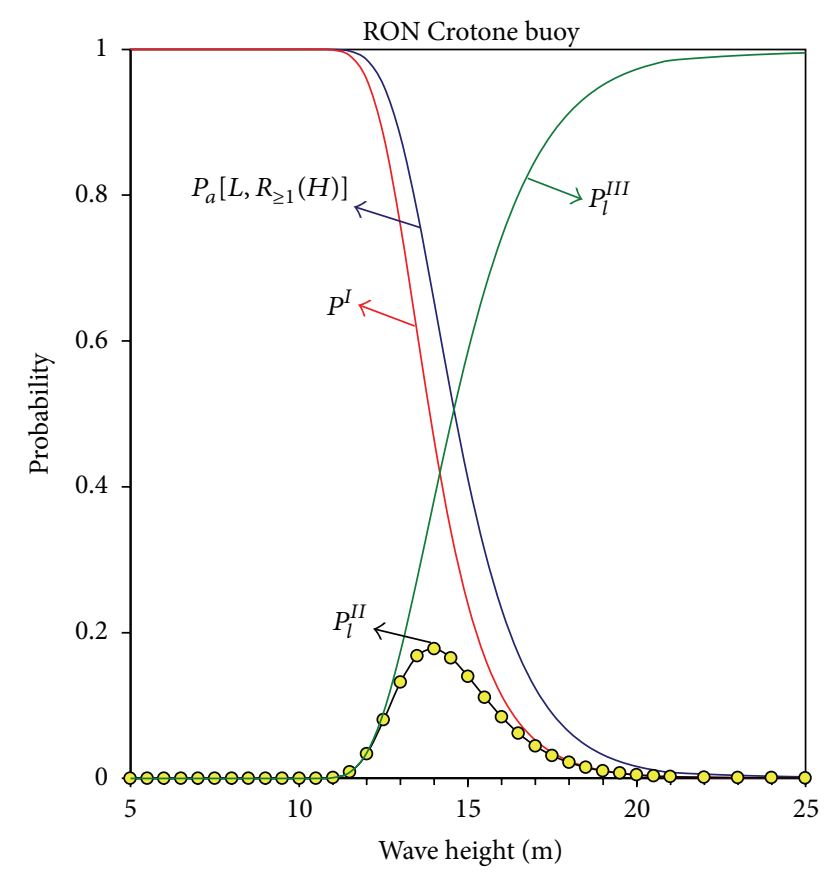

(a)

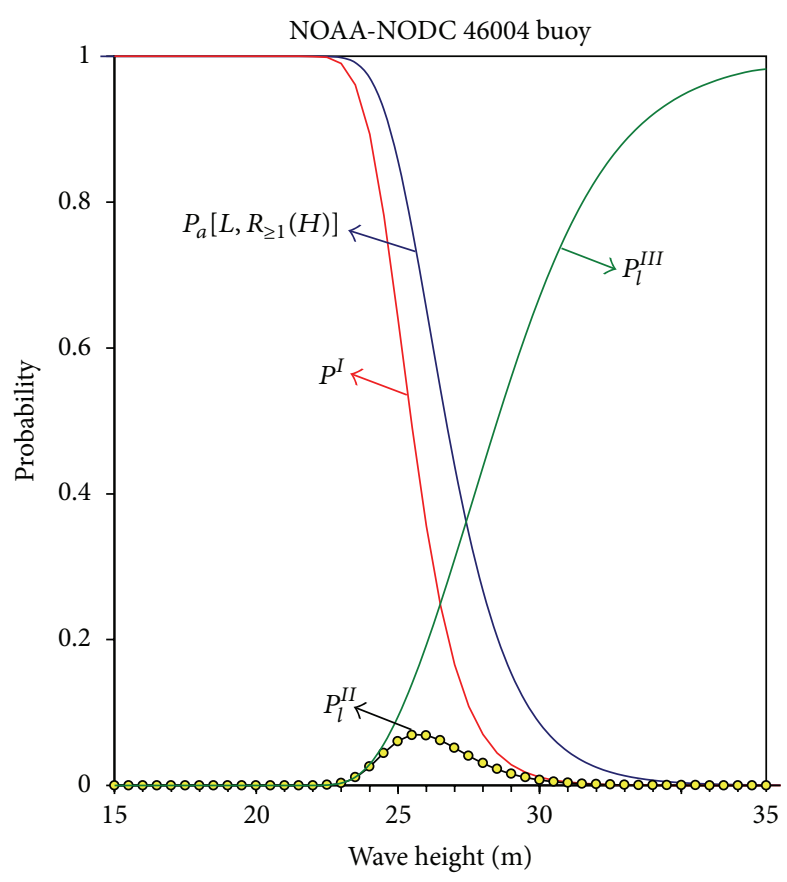

(b)

Figure 2: Probabilities of occurrence $P_{a}\left[L, R_{\geq 1}(H)\right](11), P^{I}(12)$, and the lower bound of probabilities $P^{I I}(13)$ and $P^{I I I}$ (14), which are indicated as $P_{l}^{I I}$ and $P_{l}^{I I I}$, respectively, for $L=50$ years. (a) RON buoy of Crotone (Italy); (b) NOAA-NODC 46004 buoy.

Figures 2 and 3 show the probabilities of occurrence $P_{a}\left[L, R_{\geq 1}(H)\right], P^{I}, P_{l}^{I I}$, and $P_{l}^{I I I}$, which are calculated from data of RON buoy of Crotone (Italy) and of NOAA-NODC 46004 buoy, for $L=50$ years. Note that $P_{l}^{I I}$ and $P_{l}^{I I I}$ are defined by right hand side of (15) and (16), respectively: they represent the lower bound of probabilities $P^{I I}$ and $P^{I I I}$, respectively.

It is interesting to note that if, for a fixed value of $L$, a large value of the probability is considered (0.8-0.9, e.g.), the height value achieved from $P^{I}$ curve is $3-4 \%$ smaller than wave height given by $P_{a}\left[L, R_{\geq 1}(H)\right]$ probability. This difference increases as smaller values are considered of probability.

For example, if data of Figure 2 are considered, we have that

(1) for a value of probability $P=0.8$, we find a wave height equal to $25.3 \mathrm{~m}$ from $P_{a}\left[L, R_{\geq 1}(H)\right]$ and to $24.4 \mathrm{~m}$ from $P^{I}$ (the ratio is equal to 0.964 ); in other words, for a lifetime $L=50$ years and a probability equal to 0.8 , we find a wave height, which is maximum in its own storm, equal to $25.3 \mathrm{~m}$; the height of the wave that in 50 years will be the second one in height, for $P=0.8$, will be equal to $24.4 \mathrm{~m}$;

(2) for a value of probability $P=0.2$, we find a wave height equal to $28.6 \mathrm{~m}$ from $P_{a}\left[L, R_{\geq 1}(H)\right]$ and to $26.8 \mathrm{~m}$ from $P^{I}$ (the ratio is equal to 0.939 );

(3) for a value of probability $P=0.05$, we find a wave height equal to $30.9 \mathrm{~m}$ from $P_{a}\left[L, R_{\geq 1}(H)\right]$ and to $28.4 \mathrm{~m}$ from $P^{I}$ (the ratio is equal to 0.919 ).
The probability $P^{I I I}$, in conditions (1)-(3), will be greater than $0.05,0.29$, and 0.49 , respectively.

\section{Appendix}

The following functions have been used for calculation:

$$
\begin{gathered}
P\left(H ; H_{s}=h\right)=\exp \left[-\frac{4}{1+\psi^{*}}\left(\frac{H}{h}\right)^{2}\right], \\
p\left(H ; H_{s}=h\right)=\frac{8}{1+\psi^{*}} \frac{H}{h^{2}} \exp \left[-\frac{4}{1+\psi^{*}}\left(\frac{H}{h}\right)^{2}\right]
\end{gathered}
$$

that are probability of exceedance (A.1) and probability density function (A.2) of the crest-to-trough wave height in a sea state with a given significant wave height $H_{s}=h$, where $\psi^{*}$ is the narrower bandedness parameter $[2,3]$;

$$
\bar{T}(h)=10.4 \sqrt{\frac{h}{g}}
$$

is Rice mean period, as a function of the significant wave height, in a sea state with a mean JONSWAP spectrum [26], with $g$ the acceleration due to gravity;

$$
p\left(H_{s}=h\right)=\frac{u}{w^{u}}\left(h-h_{l}\right)^{u-1} \exp \left[-\left(\frac{h-h_{l}}{w}\right)^{u}\right]
$$

is probability density function of the significant wave height in a fixed location, represented by means of a lower bounder three-parameter Weibull law. The location is identified by the 


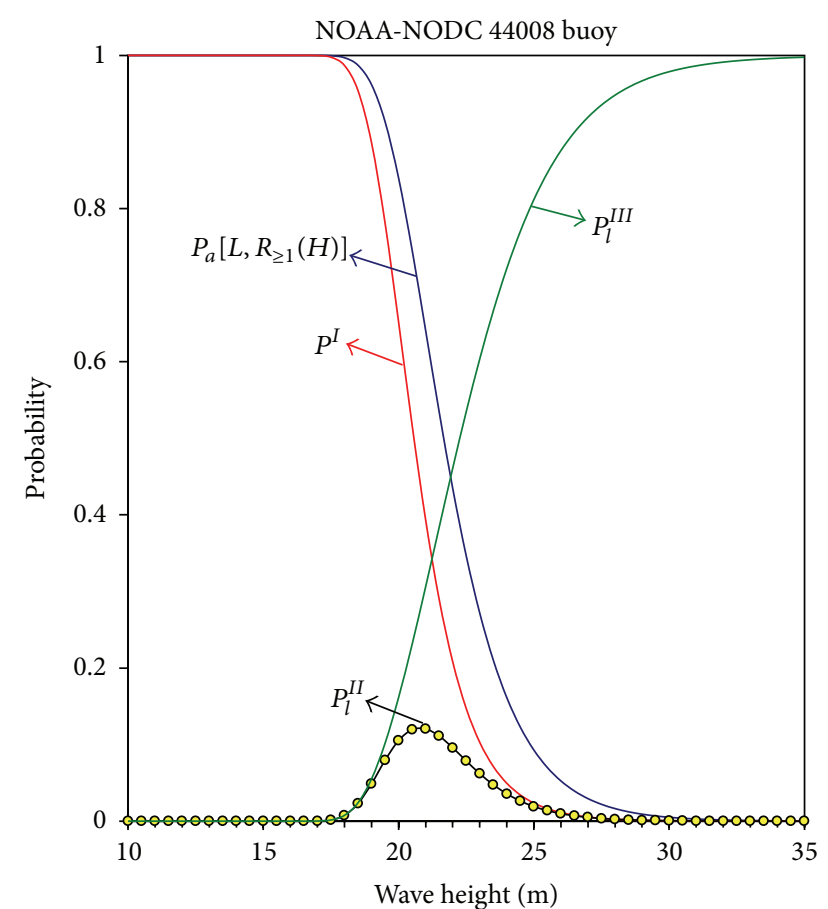

Figure 3: See caption of Figure 2. Data of NOAA-NODC 44008 buoy.

parameters $u, w$, and $h_{l}$ (see Arena, [25] for some values of the parameters);

$$
\bar{b}(a)=C_{1} \exp \left(-C_{2} a\right)
$$

is mean value of the base of the triangular storms with height $a$, which is calculated by means of an exponential regression $[3,25]$.

\section{References}

[1] P. Boccotti, "Some new results on statistical properties of wind waves," Applied Ocean Research, vol. 5, no. 3, pp. 134-140, 1983.

[2] P. Boccotti, "On coastal and offshore structure risk analysis," Excerpta of the Italian Contribution $t$ the Field of Hydraulic Engng., vol. 1, pp. 19-36, 1986.

[3] P. Boccotti, Wave Mechanics for Ocean Engineering, Elsevier Science, Oxford, UK, 2000.

[4] F. Arena and D. Pavone, "Return period of nonlinear high wave crests," Journal of Geophysical Research C, vol. 111, no. 8, Article ID C08004, 10 pages, 2006.

[5] G. Z. Forristall, "Wave crest distributions: observations and second-order theory," Journal of Physical Oceanography, vol. 30, no. 8, pp. 1931-1943, 2000.

[6] F. Fedele and F. Arena, "Weakly nonlinear statistics of high random waves," Physics of Fluids, vol. 17, no. 2, pp. 1-10, 2005.

[7] F. Arena and D. Pavone, "A generalized approach for long-term modelling of extreme crest-to-trough wave heights," Ocean Modelling, vol. 26, no. 3-4, pp. 217-225, 2009.

[8] H. Krogstad, "Height and period distributions of extreme waves," Applied Ocean Research, vol. 7, no. 3, pp. 158-165, 1985.
[9] L. E. Borgman, "Probabilities for highest wave in hurricane," Journal of the Waterways, Harbors and Coastal Engineering Division, vol. 99, no. 2, pp. 185-207, 1973.

[10] P. S. Tromans and L. Vanderschuren, "Response based design conditions in the North Sea: application of a new method," in Proceedings of Offshore Technology Conference, pp. 1-15, Houston, Tex, USA, 1995, paper OTC 7683.

[11] G. Z. Forristall, "How should we combine long and short term wave height distributions?" in Proceedings of the 27th International Conference on Offshore Mechanics and Arctic Engineering (OMAE '08), pp. 987-994, June 2008.

[12] F. Fedele and F. Arena, "Long-term statistics and extreme waves of sea storms," Journal of Physical Oceanography, vol. 40, no. 5, pp. 1106-1117, 2010.

[13] F. Arena, V. Laface, G. Barbaro, and A. Romolo, "Effects of sampling between data of significant wave height for intensity and duration of severe sea storms," International Journal of Geosciences, vol. 4, pp. 240-248, 2013.

[14] P. Boccotti, F. Arena, V. Fiamma, and G. Barbaro, "Field experiment on random-wave forces on vertical cylinders," Probabilistic Engineering Mechanics, vol. 28, pp. 39-51, 2012.

[15] P. Boccotti, F. Arena, V. Fiamma, A. Romolo, and G. Barbaro, "A small scale field experiment on wave forces on upright breakwaters," Journal of Waterway, Port, Coastal, and Ocean Engineering, vol. 138, no. 2, pp. 97-114, 2012.

[16] P. Boccotti, F. Arena, V. Fiamma, and A. Romolo, "Two small-scale field experiments on the effectiveness of Morison's equation," Ocean Engineering, vol. 57, no. 1, pp. 141-149, 2013.

[17] A. Romolo, G. Malara, G. Barbaro, and F. Arena, "An analytical approach for the calculation of random wave forces on submerged tunnels," Applied Ocean Research, vol. 31, no. 1, pp. 3136, 2009.

[18] F. Arena, "Interaction between long-crested random waves and a submerged horizontal cylinder," Physics of Fluids, vol. 18, no. 7, Article ID 076602, 2006.

[19] F. Arena and V. Nava, "On linearization of Morison force given by high three-dimensional sea wave groups," Probabilistic Engineering Mechanics, vol. 23, no. 2-3, pp. 104-113, 2008.

[20] A. Romolo and F. Arena, "Mechanics of nonlinear random wave groups interacting with a vertical wall," Physics of Fluids, vol. 20, no. 3, Article ID 036604, 2008.

[21] A. Romolo and F. Arena, "Nonlinear wave pressures given by extreme waves on an upright breakwater: theory and experimental validation," in Proceedings of the 33rd International Conference on Coastal Engineering (ICCE '12), pp. 1-15, ASCE, Santander, Spain, July 2012, paper waves.33.

[22] S. O. Rice, "Mathematical analysis of random noise," The Bell System Technical Journal, vol. 23, pp. 282-332, 1944.

[23] S. O. Rice, "Mathematical analysis of random noise," The Bell System Technical Journal, vol. 24, pp. 46-156, 1945.

[24] L. Borgman, "Maximum wave height probabilities for a random number of random intensity storms," in Proceedings of the12th Conference on Coastal Engineering, pp. 53-64, 1970.

[25] F. Arena, "On the prediction of extreme sea waves," Environmental Sciences and Environmental Computing, vol. 2, pp. 1-50, 2004.

[26] K. Hasselmann, T. P. Barnett, E. Bouws et al., "Measurements of wind-wave growth and swell decay during the joint North Sea wave project (JONSWAP)," Ergnzungsheft zur Deutschen Hydrographischen Zeitschrift Reihe, vol. A8, pp. 1-95, 1973. 


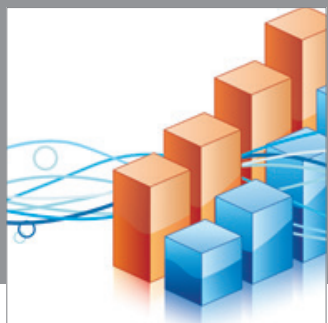

Advances in

Operations Research

mansans

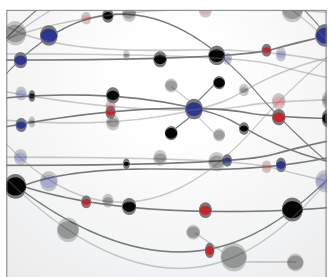

The Scientific World Journal
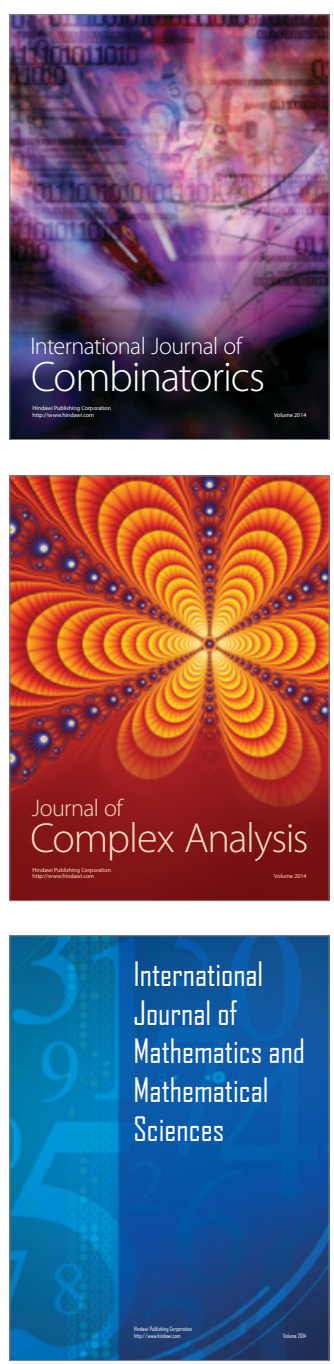
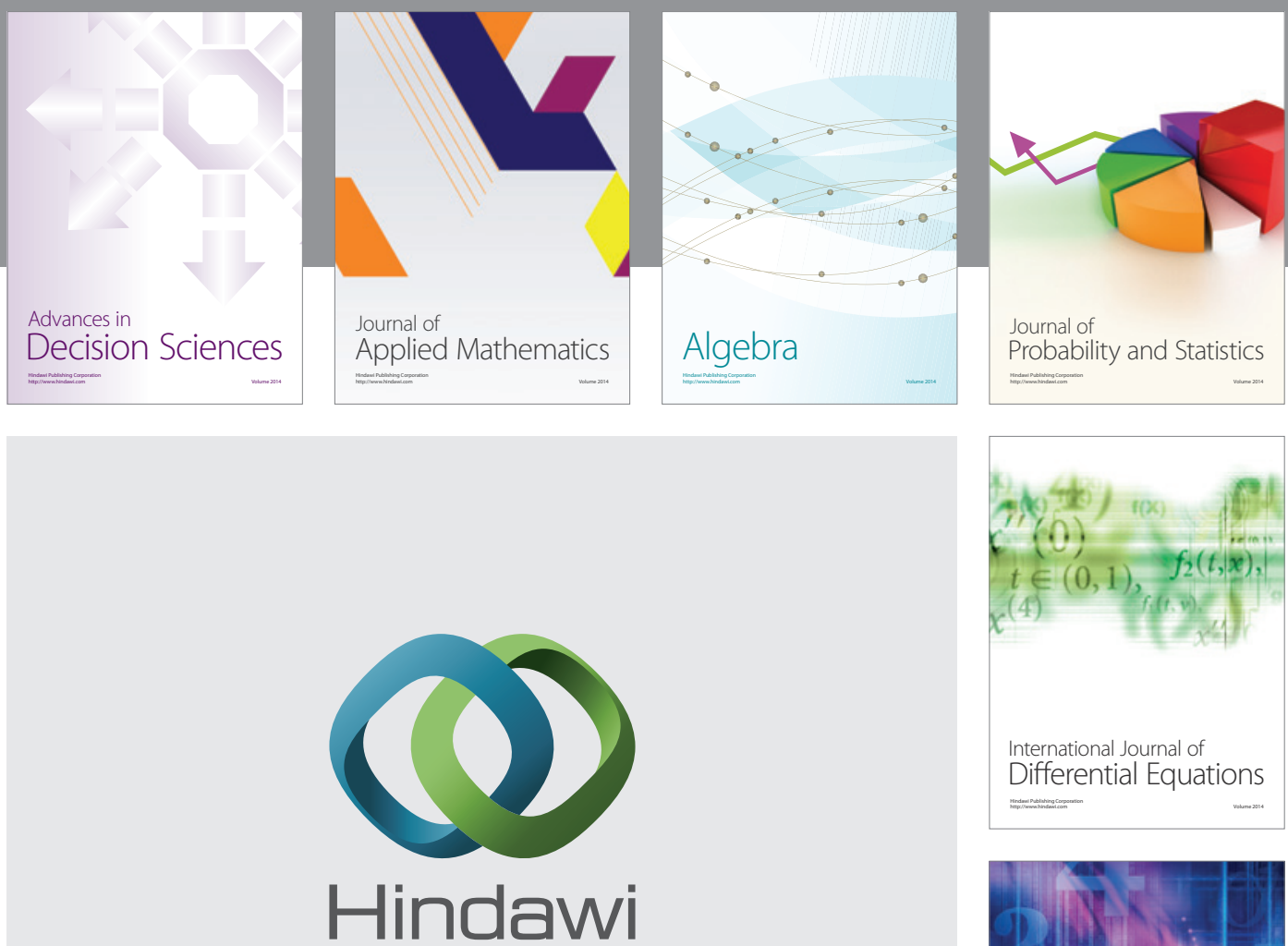

Submit your manuscripts at http://www.hindawi.com
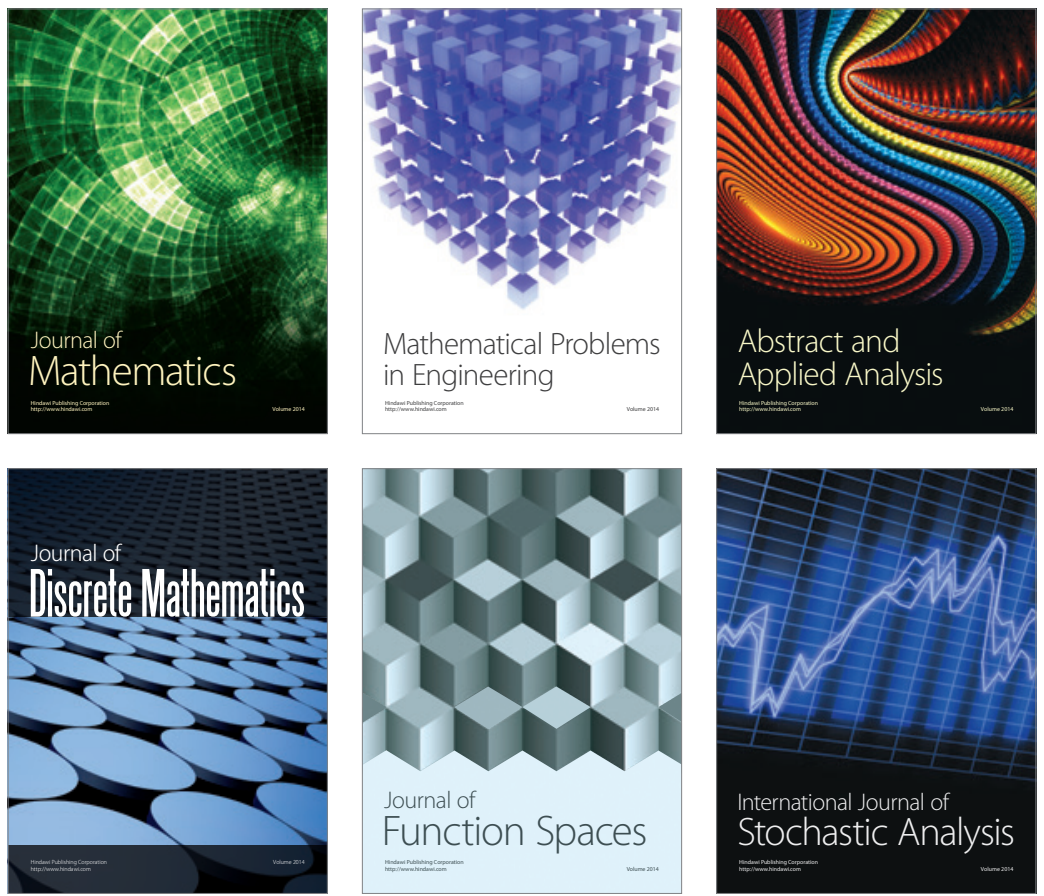

Journal of

Function Spaces

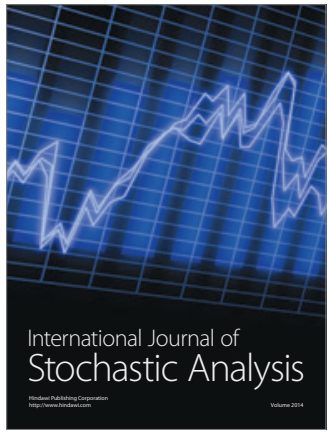

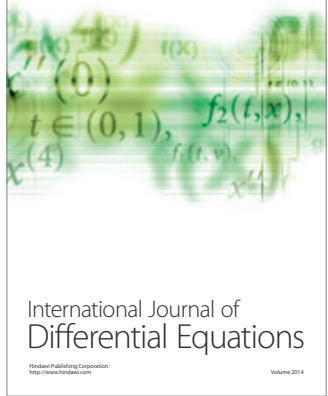
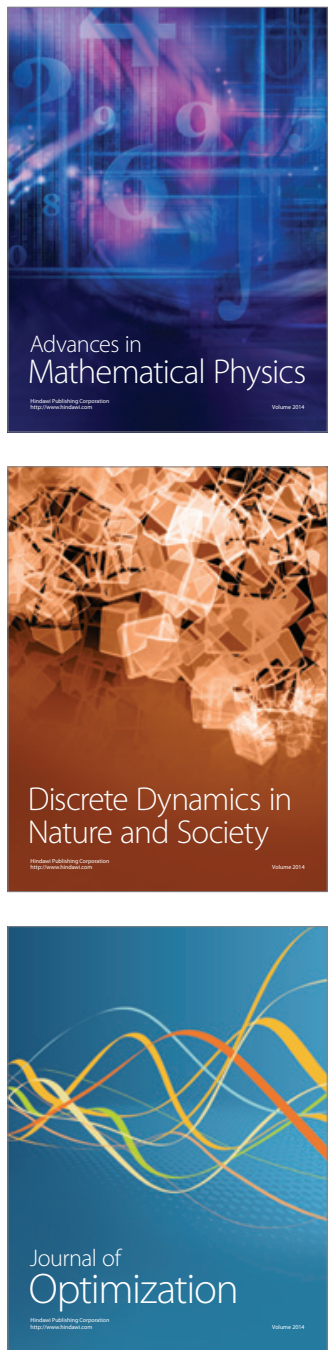